\title{
EFFICACY OF SURFACTANT ADMINISTRATION TO PRETERM INFANTS VIA THIN CATHETER VERSUS INSURE TECHNIQUE.
}

1. MBBS, FCPS

Senior Registrar and Fellow in Neonatology,

Hameed Latif Hospital, Lahore.

2. MBBS, FCPS

Senior Registrar Paediatrics,

Sandeman Provincial Hospital,

Quetta.

3. MBBS, DCH, MCPS, FCPS

Professor Paediatrics,

Shaikh Zayed Hospital, Lahore.

4. MBBS, DCH (Glasgow), MRCPCH

(London), MRCP (UK)

Professor \& HOD Paediatrics,

Shaikh Zayed Hospital, Lahore

5. MBBS, MPhil

Professor Pathology,

$\mathrm{CMH}$ Multan Institute of Medical

Sciences, Multan

6. MBBS, MRCP (London) MRCPCH (UK), DRCPCH (UK)

Consultant Paediatrician \&

Neonatologist,

Hameed Latif Hospital, Lahore.

Correspondence Address:

Dr. Mayda Riaz

Senior Registrar and Fellow in

Neonatology,

Hameed Latif Hospital, Lahore.

dr.maydariaz@gmail.com

Article received on:

19/09/2019

Accepted for publication:

11/12/2019

\section{INTRODUCTION}

Respiratory distress syndrome (RDS) is a common respiratory disease occurring in $37.28 \%$ of premature infants and $0.11 \%$ of term infants. ${ }^{1}$ It is caused by deficiency of surfactant leading to microatelactasis and decrease in lung volume. ${ }^{2}$ Prematurity is the commonest risk factor ${ }^{3,4}$ followed by white ethnicity, male gender, maternal diabetes, Caesarean section, chorioamnionitis, low birth weight, birth asphyxia, lung infections and meconium aspiration syndrome. ${ }^{4}$ The disease has mortality rate as high as $43.61 \% .^{1}$ Antenatal steroids and prophylactic surfactant therapy have significantly reduced the incidence of RDS and its associated mortality and morbidity. ${ }^{5}$ Diagnosis of RDS can be interpreted on the basis of clinical findings of tachypnea, grunting, chest retractions,
Mayda Riaz ${ }^{\text {, Shakila Asmat }}{ }^{2}$, Fouzia Shaukat ${ }^{3}$, Muhammad Aslam$^{4}$, Muhammad Tahir Majeed ${ }^{5}$,

ABSTRACT... Objectives: To compare the efficacy of administering surfactant to preterm infants using thin catheter and Intubate-Surfactant-Extubate (InSurE) techniques in terms of need of mechanical ventilation within $1^{\text {st }} 72$ hours of life. Study Design: Randomized controlled trial. Setting: Neonatal intensive care unit (NICU), Federal Postgraduate Medical Institute and Shaikh Zayed Hospital (FPGMI and SZH), Lahore. Period: From November 2014 to April 2015. \&ethods: A total of one hundred preterm infants who developed respiratory distress (RDS) and fulfiled the inclusion criteriawere enrolled in the study. The enrolled infants were administered surfactant via thin catheter technique, whereas those in Group B by InSurE technique. The infants were monitored by clinical and laboratory parameters for the need of Cosults: Majority of the preterm infants in Group A (54\%) and Group B (56\%) were born through while Group B constituted 52\% ( $n=26)$ males and 48\% ( $n=24)$ femal age in Group A and Group B was found to be $29.43 \pm 4.24$ weeks and $28.54 \pm 3.87$ weeks, espectively. Mean birth weight in Group A and Group B was found to be $1375.87+143.36$ and 1392.87+129.27 grams, respectively. Efficacy of surfactant was recorded as $64 \%(n=32)$ in group $B(p=0.04)$. Conclusion: Surfactant administration using thin catheter is significantly more efficacious than InSurE in respect of the need of mechanical Key words: $\quad$ InSurE, Respiratory Distress Syndrome, Surfactant, Thin Catheter.

Article Citation: Riaz M, Asmat S, Shaukat F, Aslam M, Majeed MT, Rafique S: Efficacy of surfactant administration to preterm infants via thin catheter versus InSurE technique. Professional Med J 2020; 27(2):431-436.

DOI: 10.29309/TPMJ/2020.27.2.4176

nasal flaring, chest radiograph and arterial blood gases. ${ }^{6}$

Conventionally, surfactant is administered via endotracheal tube followed by positive pressure ventilation. ${ }^{7}$ Endotracheal intubation is invasive procedure and positive pressure ventilation increases the likelihood of Broncho pulmonary dysplasia. ${ }^{8}$ Even short time exposure to excessive delivered tidal volume during ventilation can exacerbate lung injury and compromise the therapeutic effect of surfactant therapy. ${ }^{9}$ The method being an expensive modality is hard to afford in low income countries. Hence, there has been a great endeavour to create alternative ways of surfactant administration. 
Surfactant therapy with nasal continuous positive airway pressure (nCPAP) was found to be successful in establishing and managing the functional residual capacity of premature lungs. ${ }^{10}$ Consequently, various less invasive methods of surfactant administration like InSurE and minimally invasive surfactant therapy (MIST) were devised and many are still under trials.

In InSurE technique the infants are intubated, given surfactant followed by brief period positive pressure ventilation, extubated and then placed on nCPAP. Modification of InSurE led to invent of MIST comprising four methods of surfactant administration i.e. intrapharyngeal, thin catheter, laryngeal mask and nebulization. ${ }^{11}$ Out of these, thin catheter was found to be an effective method as it reduced the need for mechanical ventilation especially during $1^{\text {st }} 72$ hours of life..$^{12,13,14}$

Pakistan stands $4^{\text {th }}$ amongst countries with highest rate of preterm births. ${ }^{15}$ Consequential increase in the incidence of RDS is demanding of specialized NICUs and proper guidelines for surfactant administration. The situation also advocates an extreme need for practicing cost effective and non invasive method of surfactant therapy. So far, very few studies have been carried out in Pakistan to assess the effectiveness of such methods. This study aims at evaluating the benefits of surfactant administration using thin catheter and InSurE techniques in our setup.

\section{MATERIALS AND METHODS}

A randomized control trial was conducted from November 2014 to April 2015 in NICU of a university teaching, tertiary care, FPGMI and $\mathrm{SZH}$, Lahore. Approval from Institutional ethical committee and written informed consent was obtained from parents of preterm infants. Preterm infants who met inclusion criteria as given below were included in the study:

1. Preterm infants both males and females, born in Gynae and Obstetrics unit of Shaikh Zayed Hospital Lahore, at less than 32 weeks of gestation.

2. The preterm infants born through SVD or caesarean section.

3. The preterm infants who developed RDS within two hours of birth.

Preterm neonates who met exclusion criteria as given below were excluded from the study:

1. The preterm infants born with major congenital anomalies e.g. Atrial septal defect, Ventricular septal defect, Tetralogy of Fallot etc. as diagnosed on clinical examination, chest radiograph and Echocardiography.

2. The preterm infants whose parents did not give consent.

3. The preterm infants who underwent positive pressure ventilation with or without intubation in delivery room.

Respiratory distress syndrome was diagnosed clinically on manifestation of tachypnea, grunting, intercostal recessions, need for oxygen supplementation and reduced air entry on auscultation. Diagnosis was confirmed by chest radiograph and arterial blood gases (ABGs).

A total of 100 preterm infants were enrolled in the study and their data was entered in a predesigned proforma. All these infants were started nCPAP therapy with initial settings of fraction of inspired oxygen ( $\mathrm{FiO} 2$ ) $60 \%$, and positive end expiratory pressure of $6 \mathrm{~cm} \mathrm{H}_{2} 0$. Pulse oximeter was attached for monitoring of their oxygen saturation.

Group allocation was concealed in an opaque envelope. Envelope, selected through lottery method was opened and patient was assigned to a specific group i.e. Thin catheter group (Group A) and InSurE group (Group B).

Exogenous surfactant was administered to infants in Group A through a $5 \mathrm{Fr}$ flexible sterile nasogastric tube (NG tube). The NG tube was introduced in infant's trachea $1 \mathrm{~cm}$ below the level of vocal cards by using a laryngoscope. Surfactant was given at a dose of $4 \mathrm{ml} / \mathrm{kg}$ in small portions within 1-3 minutes while the infant continued spontaneous breathing on nCPAP during the procedure. The infant's oxygen saturation was continuously monitored by pulse oximeter throughout the procedure. After surfactant administration the catheter was removed. 
Surfactant was administered to infants in Group $\mathrm{B}$ by disconnecting nCPAP and passing a 2.5Fr endotracheal tube (ETT) in trachea, using laryngoscope. Depth of ETT insertion was calculated by using formula (weight in $\mathrm{kg}+6 \mathrm{~cm}$ ) and it was adjusted according to the weight of the infant. Sufactant was given through ETT at dose of $4 \mathrm{ml} / \mathrm{kg}$ in two halves and the infant received positive pressure ventilation (PPV) by ambu bag. After 10-15 minutes of PPV, ETT was removed. Oxygen saturation of the infant was monitored throughout the procedure.

This procedure in both groups was followed by placement of infants on nCPAP. The infants were then monitored by chest radiograph, oxygen saturation and $A B G$ s after two hours of surfactant administration. Thereafter the monitoring was carried out by ABGs and oxygen saturation on 8 hourly basis till 72 hrs of life. Surfactant administration was defined to be effective if it prevented mechanical ventilation in $1^{\text {st }} 72 \mathrm{hrs}$ of life and improved clinical condition of the infant.

Data was analyzed using statistical package for social sciences (SPSS) version 17.0. Descriptive statistical analyses were performed. Quantitative data like gestational age and weight was described by mean and standard deviation (SD). Qualitative data like efficacy, gender, and mode of delivery viz. spontaneous vaginal delivery (SVD) or Caesarean section (C section) was presented by frequency and percentage. The difference in efficacy in two groups was calculated using Chi square test and $p$ value of $<0.05$ was considered significant.

\section{RESULTS}

During the study period 127 preterm infants born at SZH, Lahore were assessed for inclusion in the study. Out of these, 7 infants needed resuscitation at birth, 3 had congenital anomalies while 17 infants' parents did not give consent and were excluded from the study. Remaining 100 $(\mathrm{N}=100)$ preterm infants fulfilled the criteria and were included in the study (Figure-1).

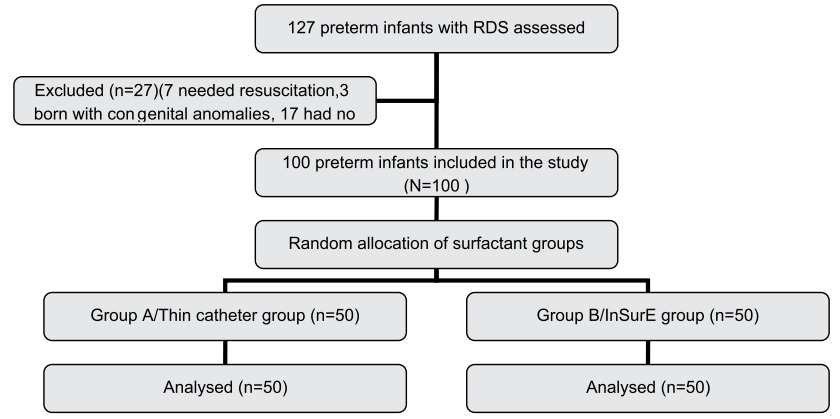

Figure-1. Flow diagram showing distribution of preterm infants in the study.

The infants were divided into two groups i.e. Group A $(n=50)$ and Group B $(n=50)$ using randomized selection as mentioned previously. In Group A, 54\% $(n=27)$ and 46\% $(n=23)$, while in Group B, 56\% $(n=28)$ and $44 \%(n=22)$ of the infants were born through $\mathrm{C}$ section and SVD respectively.

Gender distribution revealed that Group A comprised of $58 \%(n=29)$ males and $42 \%(n=21)$ females, whereas in Group B, 52\% $(n=26)$ of the preterm infants were males and $48 \%(n=24)$ were females (Figure-2).

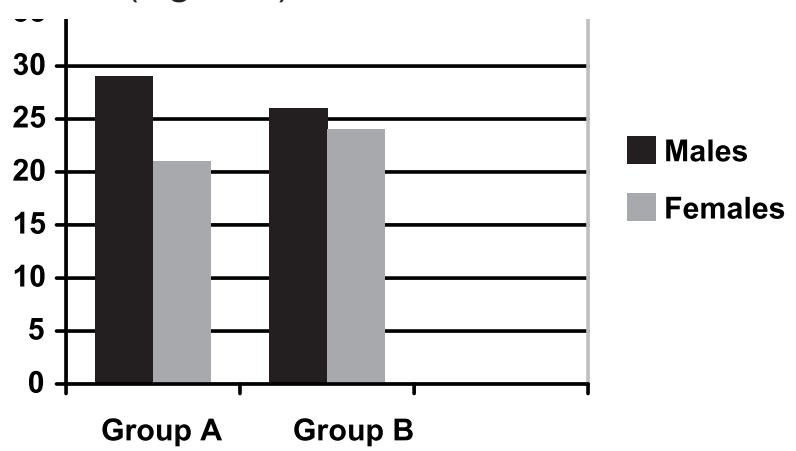

Figure-2. Gender breakdown of preterm babies in Group A and Group B.

Among patients in Group A, 46\% $(n=23)$ of preterm babies were born at 25-28 weeks of gestation and 54\% $(n=27)$ were born at 29-32 weeks. Whereas in Group B, 52\% $(n=26)$ were born at 25-28 weeks and $48 \%(n=24)$ were born at 29-32 weeks of gestation. Mean gestational age in Group A and Group B was found to be $29.43 \pm 4.24$ weeks and $28.54 \pm 3.87$ weeks, respectively.

In Group A, 50\% ( $n=25)$ of preterm babies weighed $<1200$ grams and $50 \% \quad(n=25)$ 
weighed between 1200-1500 grams. Similarly, in Group B, 58\% $(n=29)$ of the premature infants weighed $<1200$ grams and $42 \%(n=21)$ of them weighed between 1200-1500 grams. Mean birth weight was calculated as $1375.87+143.36$ and $1392.87+129.27$ gram in Group-A and B, respectively.

Statistical analysis showed no significant difference in demographic data of patients in both groups (Table-I).

Surfactant was given to patients in Group A by thin catheter and to patients in Group B by endotracheal tube. The infants were monitored for the need of mechanical ventilation within $1^{\text {st }} 72$ hours of life. Among the patients in Group A, $36 \%$ $(n=18)$, needed mechanical ventilation whereas $64 \%(n=32)$ succeeded to avoid mechanical ventilation. On the other hand, in Group B, 56\% $(n=28)$ needed mechanical ventilation and $44 \%(n=22)$ succeeded in avoiding mechanical ventilation within $1^{\text {st }} 72 \mathrm{hrs}$ of life. Statistical analysis showed significant difference $(p=0.04)$ in efficacy of surfactant administration among both groups (Table-II). Surfactant administration via thin catheter proved to be better method of surfactant administration than InSurE technique, in avoiding mechanical ventilation in $1^{\text {st }} 72 \mathrm{hrs}$ of life of preterm infants.

\begin{tabular}{|c|c|c|c|c|}
\hline & & $\begin{array}{l}\text { Thin Catheter Group } \\
\text { Group } A(n=50)\end{array}$ & $\begin{array}{l}\text { InSurE Group } \\
\text { Group B }(n=50)\end{array}$ & P-Value \\
\hline Mode of delivery & $\begin{array}{l}\text { C section (n\%) } \\
\text { SVD (n\%) }\end{array}$ & $\begin{array}{l}27(54 \%) \\
23(46 \%) \\
\end{array}$ & $\begin{array}{l}28(56 \%) \\
22(44 \%)\end{array}$ & 0.840 \\
\hline Gender & $\begin{array}{c}\text { Males n (\%) } \\
\text { Females n (\%) }\end{array}$ & $\begin{array}{l}29(58 \%) \\
21(42 \%)\end{array}$ & $\begin{array}{l}26(52 \%) \\
24(48 \%)\end{array}$ & 0.546 \\
\hline $\begin{array}{l}\text { Gestational age } \\
\text { (weeks) }\end{array}$ & $\begin{array}{l}25-28 \\
29-32\end{array}$ & $\begin{array}{l}23(46 \%) \\
27(54 \%)\end{array}$ & $\begin{array}{l}26(52 \%) \\
24(48 \%)\end{array}$ & 0.548 \\
\hline Birth weight (grams) & $\begin{array}{c}<1200 \\
>1200-1500\end{array}$ & $\begin{array}{l}25(50 \%) \\
25(50 \%)\end{array}$ & $\begin{array}{l}29(58 \%) \\
21(42 \%)\end{array}$ & 0.422 \\
\hline
\end{tabular}

Table-I. Demographic and clinical charecteristics of both groups.

\begin{tabular}{|l|c|c|c|}
\hline Efficacy & $\begin{array}{c}\text { Thin Catheter Group } \\
\text { Group A (n=50) }\end{array}$ & $\begin{array}{c}\text { InSurE Group } \\
\text { Group B (n=50) }\end{array}$ & P-Value \\
\hline Yes & $32(64 \%)$ & $22(44 \%)$ & $28(56 \%)$ \\
\hline No & $18(36 \%)$ & $50(100 \%)$ & 0.04 \\
\hline Total & $50(100 \%)$ & & \\
\hline
\end{tabular}

Table-II. Comparison of efficacy of surfactant between both groups.

\section{DISCUSSION}

Our study concluded that surfactantadministration via thin catheter is significantly effective in reducing the need for mechanical ventilation in $1 \mathrm{st} 72 \mathrm{hrs}$ of life, as compared to the conventional method (InSurE) of surfactant administration. This result is comparable to those given by Alia et $\mathrm{al}^{16}$ and Lau et al. ${ }^{17}$ In contrast to our results, Mohammad izadeh et $\mathrm{al}^{18}$ concluded no difference in need for mechanical ventilation among both methods.

In the study, we found no significant difference in demographic data (gestational age, birth weight, gender, mode of delivery) among both groups of preterm infants offered surfactant administration, which is comparable to results given by other studies. ${ }^{18,19}$

Surfactant administration through thin catheter has few advantages over InSurE technique. Thin catheter provides surfactant while the infant is breathing spontaneously, thus avoids use of positive pressure ventilation. It also allows infants to maintain function of the glottis and continue spontaneous breathing. On the other hand, InSurE technique is associated with sedation or analgesia, regular intubation and a short period of positive pressure ventilation. ${ }^{20}$ 
According to Rigo et $\mathrm{al}^{21}$, the risk of early CPAP failure, BPD and death has been reduced by use of thin catheter, when compared to InSurE technique. Studies ${ }^{22}$ also show, that preterm survival rate is improved when surfactant administration via thin catheter technique is used in combination with CPAP.

Further trials need to be conducted in other neonatal units of Pakistan on a larger scale, so as to establish the efficacy of surfactant administration through thin catheter. A good follow up of these patients needs to be maintained for assessing long term outcomes. It is imperative to generate proper institutional guidelines for surfactant administration to preterm infants along with use of noninvasive ventilation techniques to attain a better outcome in these patients.

With the use of thin catheter in preterm infants with RDS, the survival rate can be improved and short and long term complications associated with positive pressure ventilation can be prevented, that will ultimately improve the preterm survival rate in our country.

\section{CONCLUSION}

We concluded that administration of surfactant to preterm babies using thin catheter is significantly effective when compared to InSurE technique as far as requirement of mechanical ventilation in $1^{\text {st }}$ $72 \mathrm{hrs}$ of life is considered. The technique is cost effective, easy to perform and can be carried out in less equipped neonatal setups.

\section{Copyright(C) 11 Dec, 2019.}

\section{REFERENCES}

1. Ghafoor T, Mahmud S, Ali S, Dogar SA. Incidence of respiratory distress syndrome. J Coll Physicians Surg Pak. 2003 May; 13(5):271-3.

2 .Reuter S, Moser C, Baack M. Respiratory distress in the newborn. Pediatr Rev. 2014 Oct; 35(10):417-428.

3. Dyer J. Neonatal respiratory distress syndrome: Tackling A Worldwide Problem. P T. 2019; 44(1): 1214.
4. Monica, Nasir F, Pamela S, Juan QL, Li J. Recent understanding of pathophysiology, risk factors and treatments of neonatal respiratory distress syndrome: A review. Sci Lett 2017; 5(1):70-78.

5. Pickerd N, Kotecha S. Pathophysiology of respiratory distress syndrome. Paediatrics and Child Health. 2009; 19(4):153-157.

6. Jobe A. Surfactant for respiratory distress syndrome. Neo Reviews. 2014 June; 15(6):e236-e245.

7. Sweet D.G, Carnielli V et al. European consensus guidelines on the management of respiratory distress syndrome - 2016 update. Neonatology. 2017; 111(2):107-125.

8. American Thoracic Society. Respiratory distress syndrome of the newborn. Chapter 19 197-205. Available at:https://www.thoracic.org/patients/patientresources/breathing-in-america/resources/chapter-19respiratory-distress-syndr.pdf.

9. DiBlasi RM. Nasal Continuous positive airway pressure (CPAP) for the respiratory care of the newborn infant. Respir Care. 2009 Sep; 54(9):12091235.

10. Pfister RH, Soll R. Initial respiratory support of preterm infants: The role of CPAP, the INSURE Method, and noninvasive ventilation. Clin Perinatol . 2012 Sep; 39(3):459-481.

11. Shim GH. Update of minimally invasive surfactant therapy. Korean J Pediatr. 2017 Sep; 60(9): 273-281.

12. Barkhuff WD, Soll R.F. Novel surfactant administration techniques: Will they change outcome? Neonatology. 2019; 115:411-422.

13. Canals FJ, Vizcaíno C, Ferrández MJ, Serrano MI, Vázquez C, Quiles JL, et al. Minimally invasive surfactant therapy: New age. J Neonatal Biol. 2015; 4(3): 182. doi:10.4172/2167-0897.1000182.

14. Kanmaz HG, Erdeve O, Canpolat FE, Mutlu B, Dilmen $U$. Surfactant administration via thin catheter during spontaneous breathing: Randomized controlled trial. Pediatrics. 2013 Feb; 131(2):e502-509.

15. Blencowe $H$, Cousens $S$, Oestergaard $M Z$, Chou $D$, Moller $A B$, Narwal $R$ et al. National, regional and worldwide estimates of preterm birth. The Lancet. 2012 June; 379(9832):2162-72.

16. Halim A, Shirazi H, Riaz S, Gul SS, Ali W. Less invasive surfactant administration in preterm infants with respiratory distress syndrome. JCPSP. 2019; 29 (3): 226-230. 
17. Lau CSM, Chamberlain RS, Sun S. Less invasive surfactant administration reduces the need for mechanical ventilation in preterm infants: A meta-analysis. Glob Pediatr Health. 2017; 4:2333794X17696683.

18. Mohammadizadeh $M$, Ardestani AG, Sadeghnia AR. Early administration of surfactant via a thin intratracheal catheter in preterm infants with respiratory distress syndrome: Feasibility and outcome. J Res Pharm Pract. 2015 Jan- Mar; 4(1):3136.

19. Bao Y, Zhang G, Wu M, Ma L, and Zhu J. A pilot study of less invasive surfactant administration in very preterm infants in a Chinese tertiary center. BMC Pediatrics. 2015 Mar; 15:21.
20. Herting E, Hartel C, Göpel W. Less invasive surfactant administration (LISA): Chances and limitations. Arch Dis Child Fetal Neonatal Ed. 2019 July; 0: F1-F5.

21. Rigo V, Lefebvre C, Broux I. Surfactant instillation in spontaneously breathing preterm infants: A systematic review and meta-analysis. Eur J Pediatr. 2016 Dec; 175(12):1933-1942.

22. Gortner L, Schüller SS, Herting E. Review demonstrates that less invasive surfactant administration in preterm neonates leads to fewer complications. Acta Paediatr. 2018 May; 107(5):736-743.

\begin{tabular}{|c|c|c|c|}
\hline \multicolumn{4}{|c|}{ AUTHORSHIP AND CONTRIBUTION DECLARATION } \\
\hline Sr. \# & Author(s) Full Name & Contribution to the paper & Author(s) Signature \\
\hline 2 & Shakila Asmat & $\begin{array}{l}\text { Propsed topic, basic study } \\
\text { design, methodology and } \\
\text { manuscript writing. } \\
\text { Data collection, statistical } \\
\text { analysis and intepretation of } \\
\text { results }\end{array}$ & Shatila.A \\
\hline 3 & Fouzia Shaukat & $\begin{array}{l}\text { Data collection, statistical } \\
\text { analysis and intepretation of } \\
\text { results. }\end{array}$ & 4 \\
\hline 4 & Muhammad Aslam & $\begin{array}{l}\text { Literature review and } \\
\text { referencing \& quality insure }\end{array}$ & \\
\hline 5 & Muhammad Tahir Majeed & $\begin{array}{l}\text { Proposed topic, basic study } \\
\text { design, methodology and } \\
\text { manuscript writing. }\end{array}$ & \\
\hline 6 & Sajjad Rafique & $\begin{array}{l}\text { Literature review and } \\
\text { referencing and quality } \\
\text { insurer. }\end{array}$ & \\
\hline
\end{tabular}

